\title{
Avenanthramide supplementation reduces eccentric exercise-induced inflammation in young men and women
}

Tianou Zhang ${ }^{1}$, Tong Zhao ${ }^{2}$, Yuzi Zhang ${ }^{2}$, Tao Liu², Gilles Gagnon³ Jacqueline Ebrahim³ , Jodee Johnson4, Yi-Fang Chu ${ }^{4}$ and Li Li Ji $2^{2^{*}}$ (D)

\begin{abstract}
Background: Avenanthramides (AVA) are a group of di-phenolic acids found only in oats and have shown antioxidant and anti-inflammatory effects in vitro and in vivo. Eccentric muscle contraction is intimately involved in rigorous exercise that activates systemic and local inflammatory responses. The objective of the study is to evaluate whether chronic AVA supplementation could attenuate peripheral inflammatory and immunological markers in human subjects in response to an acute bout of downhill running (DR).

Methods: Eleven male and thirteen female subjects voluntarily participated in this double-blinded, randomized controlled study and were randomly divided into AVA-supplemented (AVA) or control (C) groups. All subjects conducted a DR protocol at $-10 \%$ grade with an intensity equivalent to $75 \%$ of their maximal heart rate. Blood samples were collected at rest and various time points (0-72 h) after DR (PRE). After an 8-week washout period, participants received two cookies daily containing either $206 \mathrm{mg} / \mathrm{kg}$ (AVA) or $0 \mathrm{mg} / \mathrm{kg}$ (C) AVA for 8 weeks. Following the oat supplementation regimen, the DR and blood sampling protocols were repeated (POST). Plasma inflammatory and immunological markers were measured using Multiplex immunoassay and muscle soreness was evaluated with pain rating scale.
\end{abstract}

(Continued on next page)

\footnotetext{
* Correspondence: Ilji@umn.edu

${ }^{2}$ Laboratory of Physiological Hygiene and Exercise Science (LPHES), School of Kinesiology, University of Minnesota-Twin Cities, Minneapolis, MN 55455, USA

Full list of author information is available at the end of the article
}

(C) The Author(s). 2020 Open Access This article is licensed under a Creative Commons Attribution 4.0 International License, which permits use, sharing, adaptation, distribution and reproduction in any medium or format, as long as you give appropriate credit to the original author(s) and the source, provide a link to the Creative Commons licence, and indicate if changes were made. The images or other third party material in this article are included in the article's Creative Commons licence, unless indicated otherwise in a credit line to the material. If material is not included in the article's Creative Commons licence and your intended use is not permitted by statutory regulation or exceeds the permitted use, you will need to obtain permission directly from the copyright holder. To view a copy of this licence, visit http://creativecommons.org/licenses/by/4.0/ The Creative Commons Public Domain Dedication waiver (http://creativecommons.org/publicdomain/zero/1.0/) applies to the data made available in this article, unless otherwise stated in a credit line to the data. 
(Continued from previous page)

Results: DR increased plasma creatine kinase $(C K)$ activity $(P<0.01)$ during PRE, but the response was reduced at 24 and $48 \mathrm{~h}$ during POST vs. PRE regardless of AVA status $(P<0.05)$. Neutrophil respiratory burst (NRB) levels were elevated at 4 and $24 \mathrm{~h}(P<0.05)$ during PRE but were significantly decreased at $0-48 \mathrm{~h}$ during POST vs. PRE $(P<0.05$ or 0.01$)$. Granulocyte-colony stimulating factor (G-CSF), the neutrophil stimulating cytokine, was also increased in response to DR but showed lower levels in AVA compared to C during POST Vs. PRE $(P<0.05)$. Plasma interleukin-6 (IL-6) content showed an increase at 0 and $4 \mathrm{~h}$ during PRE and $0 \mathrm{~h}$ during POST $(P<0.01)$, whereas during POST there was a trend toward a lower IL-6 level in AVA vs. C ( $P=0.082)$. Plasma levels of anti-inflammatory agent interleukin-1 receptor antagonist (IL-1Ra) showed an increase at $4 \mathrm{~h}$ during PRE, and was significantly elevated in AVA vs. C during POST. Both soluble vascular cell adhesion molecule-1 (sVCAM-1) and monocyte chemoattractant protein-1 (MCP-1) contents increased at 0 and $24 \mathrm{~h}$ post DR during PRE as well as POST sessions, however, sVCAM-1 content was lower in AVA vs. $C$ during POST $(P<0.05)$ and MCP-1 levels were below resting level at 24,48 and $72 \mathrm{~h}$ during POST $(P<0.05)$. DR increased muscle pain at all post-DR time points $(P<0.01)$, but the pain level was alleviated by oat supplementation at 48 and $72 \mathrm{~h}$ during POST regardless of AVA treatment $(P<0.05)$.

Conclusions: Oat AVA supplementation reduced circulatory inflammatory cytokines and inhibited expression of chemokines and cell adhesion molecules induced by DR.

Trial registration: ClinicalTrials.gov identifier: NCT02584946. Registered 23 October 2015.

Keywords: Avenanthramide, Downhill running, Inflammation, Chemokines, Cytokines

\section{Introduction}

Eccentric exercise-induced muscle damage is a major physio-pathological problem associated with unaccustomed exercise and sports. Downhill running (DR) as one form of eccentric exercise lengthens lower-extremity muscle groups during contraction, leading to macro and micro muscle injury, such as reduced excitationcontraction coupling, sarcomere disruption, torn myofibers, and microstructural damage [1-4]. Damaged muscle fibers are known to release pro-inflammatory cytokines such as interleukin (IL)- $1 \beta$ and tumor necrosis alpha (TNF- $\alpha$ ), which stimulate the expression of various cell adhesion molecules (CAMs), such as intercellular adhesion molecules (ICAMs) and vascular adhesion molecules (VCAMs) on the surface of endothelial cells. Furthermore, these interactions induce chemoattractants (e.g. MCP-1) and pro-inflammatory cytokines (e.g., IL-6, IL-8) release [5]. Adhesion molecules expressed on the surface of endothelial cells can attract phagocytic cells like monocytes and neutrophils to migrate to the injury site [6]. Monocytes are differentiated into M1 macrophage which promotes inflammation, while neutrophils are involved in the neutrophil respiratory burst (NRB) that produce reactive oxygen species (ROS) catalyzed by NADPH oxidase [7-9]. These spacial and temporal events take place during 0 to $24 \mathrm{~h}$ after the cessation of eccentric exercise. It is noteworthy that although the above cytokines and myokines participate in and promote muscle inflammatory responses ( 0 to $48 \mathrm{~h}$ ) after injury and can lead to reduced muscle metabolic and contractile function, they also play important roles in muscular regeneration and remodeling during the recovery process [9].
Due to the critical role which inflammation plays in eccentric exercise-induced muscle damage, research has long been focused on containing and reducing inflammatory responses using various pharmaceutical, physical and nutritional means [10]. Among these treatment strategies, avenanthramides (AVA), a group of diphenolic compounds found only in oats, have demonstrated potent anti-inflammatory functions in vitro and in vivo [11-16]. As the name implies, the structure of AVA includes an anthranilate derivative and a phenylpropanoid derivative linked by an amide (pseudo peptide) bond [17]. Previous studies have shown that AVA are bioavailable to rats [18] and human [19, 20]. Importantly, the anti-inflammatory effect AVA demonstrated in various studies is linked to its ability to inhibit NF- $\mathrm{kB}$ activity and the expression of pro-inflammatory cytokines and chemotactins [15, 16, 21-23]. For example, 8 weeks of dietary AVA supplementation was shown to effectively reduce DR-induced muscle damage (marked by creatine kinase, CK, release), neutrophil respiratory burst (NRB) and plasma inflammatory cytokine levels in college-age women [14]. Furthermore, pain sensation resulting from lengthening muscle contraction during DR was attenuated among the subjects. These findings suggest that AVA may be used as a potential nutritional supplement in coping with muscle and systemic inflammation after an exercise stress.

Despite the efficacy AVA has demonstrated in vitro and in vivo, the precise mechanism by which it inhibits immunoreactive cells to regulate chemokines and cell adhesion molecules is largely unclear. Furthermore, all the previous clinical studies on AVA were conducted in female subjects, and this gender-specific feature has shed 
some doubts on AVA's general utility as a dietary supplement. Thus, the purpose of the study is to evaluate the effects of chronic AVA supplementation on peripheral blood inflammatory markers induced by DR in both male and female subjects. We hypothesized that: (1) DR could cause significant muscle damage and associated increases in plasma pro-inflammatory cytokines and chemokines in human subjects; (2) AVA supplementation would decrease DR-induced muscle damage, neutrophil ROS generation, and inflammatory cytokine and chemokine levels in blood circulation; and (3) AVA supplementation would reduce subjects' pain sensation during and after DR.

\section{Methods}

\section{Subjects}

Eleven male and thirteen female non-obese subjects (Age: $23.0 \pm 1.2$ years, BMI: $22.3 \pm 0.8 \mathrm{~kg} / \mathrm{m}^{2}, \quad \mathrm{HR}_{\max }$ : $191.3 \pm 2.3 \mathrm{bpm}$ ) were recruited from the Twin Cities community to participate in this double-blinded, randomized controlled trial (ClinicalTrials.gov identifier: NCT02584946). All participants were instructed to sign informed consent approved by Institutional Review Board at University of Minnesota (UMN) before being enrolled into the study. Participants were asked to take the Health History and Gastrointestinal Tolerability Questionnaires to ensure that they met selection criteria. The Exclusion Criteria included gastrointestinal malabsorption, clinically significant disorders of circulatory, respiratory, digestive, urinary and nervous systems and related treatment medications, major trauma or surgery in the past 3 months, cancer in the prior 2 years, smoking, drinking alcohol $>5$ drinks/week, allergic to oat products, nonsteroidal anti-inflammatory drugs (NSAI DS> $800 \mathrm{mg}$ ibuprofen/week), and using nutraceuticals and vitamin supplementation. Women who are pregnant or lactating were also excluded. Over the counter or prescription medication consumption within the past 4 weeks were recorded. The following people who had moderate-intensity cardiorespiratory exercise $\geq 150 \mathrm{~min} /$ week ( $\geq 30 \mathrm{~min} / \mathrm{d}$ on $\geq 5 \mathrm{~d} /$ week), vigorous-intensity cardiorespiratory exercise $\geq 75 \mathrm{~min} /$ week $(\geq 20 \mathrm{~min} / \mathrm{d}$ on $\geq 3$ $\mathrm{d} /$ week), or a combination of moderate- and vigorousintensity exercise to achieve a total energy expenditure of $\geq 500-1000 \mathrm{MET} / \mathrm{min} \cdot \mathrm{wk}$. were not permitted to participate in the study [24].

\section{Dietary supplementation}

Participants were randomly assigned to two dietary groups, consuming oat cookies containing AVA $(n=12)$ or minimal AVA $(\mathrm{C}, n=12)$ daily for 8 weeks. The cookies AVA group received contained $206 \mathrm{mg} / \mathrm{kg}$ AVA, whereas the cookies $C$ group received had nondetectable AVA. Each cookie was made of $30 \mathrm{~g}$ oat flour and baked at $212{ }^{\circ} \mathrm{F}$ for $15 \mathrm{~min}$ to avoid excessive AVA degradation. Final AVA contents in the AVA and C cookie was $10.3 \mathrm{mg} /$ cookie (20.6 mg/day) and $0 \mathrm{mg} /$ cookie $(0 \mathrm{mg} /$ day), respectively.

\section{Downhill running protocol}

A maximal exercise test $\left(\mathrm{VO}_{2 \max }\right.$ test $)$ was performed experiment began to estimate maximum heart rate $\left(\mathrm{HR}_{\max }\right)$ and calculate target heart rate for the DR test. After an overnight fast, the participants reported to the Laboratory of Physiological Hygiene and Exercise Science to perform a DR protocol. After warm-up on the treadmill for $5 \mathrm{~min}$ at $0 \%$ grade, the subjects started 4 bouts of DR with 15 min each at $-10 \%$ grade. The treadmill speed was manually adjusted at 5-min intervals to keep the participant's heart rate at $75 \%$ of $\mathrm{HR}_{\max }$. DR bouts were separated by $5 \mathrm{~min}$ of rest. Blood samples were taken at rest, immediately after DR $(0 \mathrm{~h})$, and at 4 , 24, 48 and $72 \mathrm{~h}$ post DR. Rated perceived exertion (RPE) score on 6-20 scale (Borg scale) was evaluated in the last minute of each of the $15 \mathrm{~min} \mathrm{DR}$, and at each time point of during the post-DR time period. This DR protocol performed prior to dietary supplementation regimen (PRE) was followed by an 8-week washout period, and repeated after the 8-week dietary supplementation as described before (POST). The DR protocols and testing conditions were also kept the same during both sessions, such as the subjects' relative heart rate $\left(\% \mathrm{HR}_{\max }\right)$, room temperature, humidity and ventilation. All sessions were monitored by laboratory personnel who were trained in First Aid and exercise physiology. The entire experimental design of the study is depicted in Fig. 1.

\section{Blood collection and biomarker measurement}

Mixed venous blood was drawn from the antecubital vein into one EDTA-coated vacutainer tube and one heparin sodium-coated vacutainer tube $(10 \mathrm{ml}$ each). $100 \mu \mathrm{l}$ whole blood was transferred from EDTA-coated vacutainer tube to a $5 \mathrm{ml}$ polystyrene tube for NRB test on flow cytometer. The heparin sodium-coated tube was immediately centrifuged at $3000 \mathrm{x} \mathrm{g}$ for $15 \mathrm{~min}$ at $4{ }^{\circ} \mathrm{C}$ to obtain plasma. Plasma was removed by aspiration and frozen at $-80^{\circ} \mathrm{C}$.

\section{Muscle damage marker and blood ROS production}

Plasma creatine kinase (CK) activity was measured as a marker of muscle fiber damage with a colorimetric method using a microplate reader (BioAssay Systems). Briefly, $10 \mu \mathrm{l}$ plasma samples were added into separate wells in a 96-well plate, and $100 \mu \mathrm{l}$ reconstituted reagents $(10 \mu \mathrm{l}$ substrate solution, $100 \mu \mathrm{l}$ assay buffer and $1 \mu \mathrm{l}$ enzyme mix) were added. Samples were incubated at $37^{\circ} \mathrm{C}$ for $20 \mathrm{~min}$ and the plate was read at OD340 $\mathrm{nm}$ at 20th min and 40th min. 


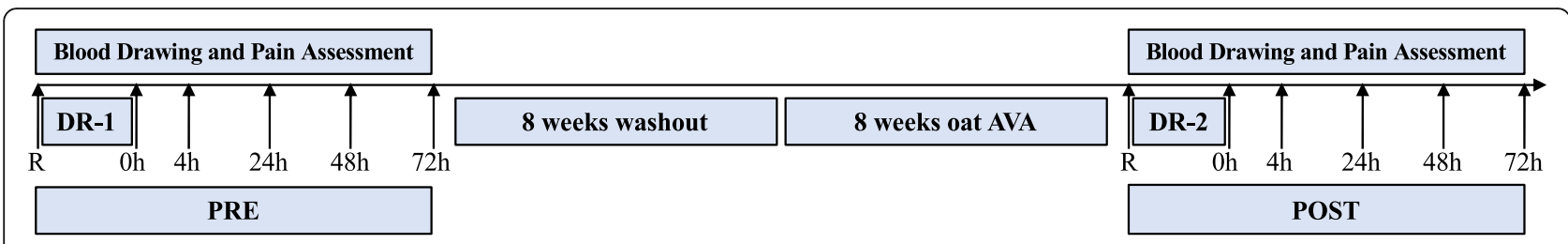

Fig. 1 Study Design

Neutrophil Respiratory Burst (NRB) was measured with a neutrophil respiratory burst assay kit (Cayman) and data were collected by BD Accuri C6 flow cytometer. Briefly, $100 \mu \mathrm{l}$ whole blood was added to a polypropylene tube containing $10 \mu \mathrm{l} 10 \mathrm{X}$ dihydrorhodamine (DHR)-123. After incubation at $37^{\circ} \mathrm{C}$ for $15 \mathrm{~min}, 25 \mu \mathrm{l}$ $5 \mathrm{X}$ phorbol myristate acetate (PMA) was added and the assay mixture was incubated at $37^{\circ} \mathrm{C}$ for $45 \mathrm{~min}$. After addition of $2 \mathrm{ml}$ red blood cell (RBC) lysis buffer, the tube was incubated at $37{ }^{\circ} \mathrm{C}$ for $10 \mathrm{~min}$ and centrifuged for $10 \mathrm{~min}$ at room temperature at $500 \times \mathrm{g}$. Supernatant was discarded and the cell pellet was resuspended in 0.5 $\mathrm{ml}$ assay buffer. DHR-123 was converted to a fluorescent compound rhodamine- 123 by ROS, and the latter one emitted a green fluorescence $(\sim 530 \mathrm{~nm})$ similar to fluorescein isothiocyanate (FITC) which was detectable in the FL-1 channel of the flow cytometer.

\section{Cell adhesion molecules and inflammatory cytokines}

Inflammatory cytokine (IL-6), anti-inflammatory cytokine (IL-1Ra), cell adhesion molecule (sVCAM-1), colony stimulating factor (G-CSF) and chemotactic cytokine (MCP-1) were measured with Multiplex assay (R\&D System). In general, $12.5 \mu$ l human plasma sample was added to a mixture of color-coded beads pre-coated with antibodies that capture specific analytes. Biotinylated detection antibodies were added and formed an antibody-antigen sandwich specific to the analytes, and phycoerythrin (PE)-conjugated streptavidin were bound to the biotinylated detection antibodies. Polystyrene beads were detected on Bio-Plex 200 System (Bio-Rad), with one laser determining the analyte and the second laser measuring the magnitude of the PE-derived signal in proportion to the amount of analyte bound.

\section{Pain rating scale}

For all visits, ratings of pain and leg muscle soreness were collected using a visual analog scale after instructing participants to squat to an approximate knee angle of $90^{\circ}$ and with hands on hips. Participants were prompted to place a vertical line along a $10 \mathrm{~cm}$ line segment with the left terminus representing no pain or soreness and the right terminus representing the worst possible pain or soreness. The distance from the left terminus to the vertical line was measured in millimeters and recorded.

\section{Data analysis}

A three-way repeated measure ANOVA was conducted using SPSS (version 22) statistical software. The three main factors are (a) Supplementation: POST vs. PRE; (b) Exercise: timing with respect to DR; and (c) AVA: AVA vs. C. The standard error of estimate of the ANOVA was used to complete the planned comparisons. Significance level was adjusted and set at the quotient of 0.05 divided the number of comparison groups. Interaction effects were also measured between Supplementation, Exercise and AVA.

\section{Results}

\section{Muscle damage and oxidative stress markers}

Plasma CK activity, a well-known marker of muscle membrane damage and leakage, was significantly increased after DR at all time points $(P<0.01)$ during PRE session (Fig. 2). During the POST session, CK activity was also elevated following DR at most time points $(P<$ 0.05 ), but not at $72 \mathrm{~h}$. Overall, CK activity during POST session was significantly decreased compared to PRE session $(P<0.05$, timexsupplementation), while at 24 and $48 \mathrm{~h}$ it was 19.5 and $23.6 \%$ lower $(P<0.05)$, respectively, than their PRE counterparts. No difference in CK activity was found between subjects receiving AVA or C treatment.

NRB was measured in blood samples collected immediately following each visit as a biomarker for ROS generation (Fig. 3). During PRE session, NRB was elevated by $70.2 \%(P<0.01)$ at $4 \mathrm{~h}$ and $52.2 \%(P<0.05)$ at $24 \mathrm{~h}$ following DR. These DR-induced changes, however, were not observed during POST session. NRB level was lowered at $0 \mathrm{~h}(P<0.05), 4 \mathrm{~h}$ and $24 \mathrm{~h}(P<0.01)$, and 48 $\mathrm{h}(P<0.05)$ during POST session compared to the respective values during PRE session. Furthermore, there was a significant interaction effect between time and AVA dose $(P<0.05)$ during POST session, showing AVA-supplemented group had lower NRB percentage than $C$.

G-CSF stimulates the proliferation of granulocytes and is one of the most important regulators of neutrophil function. Plasma G-CSF concentrations was significantly 


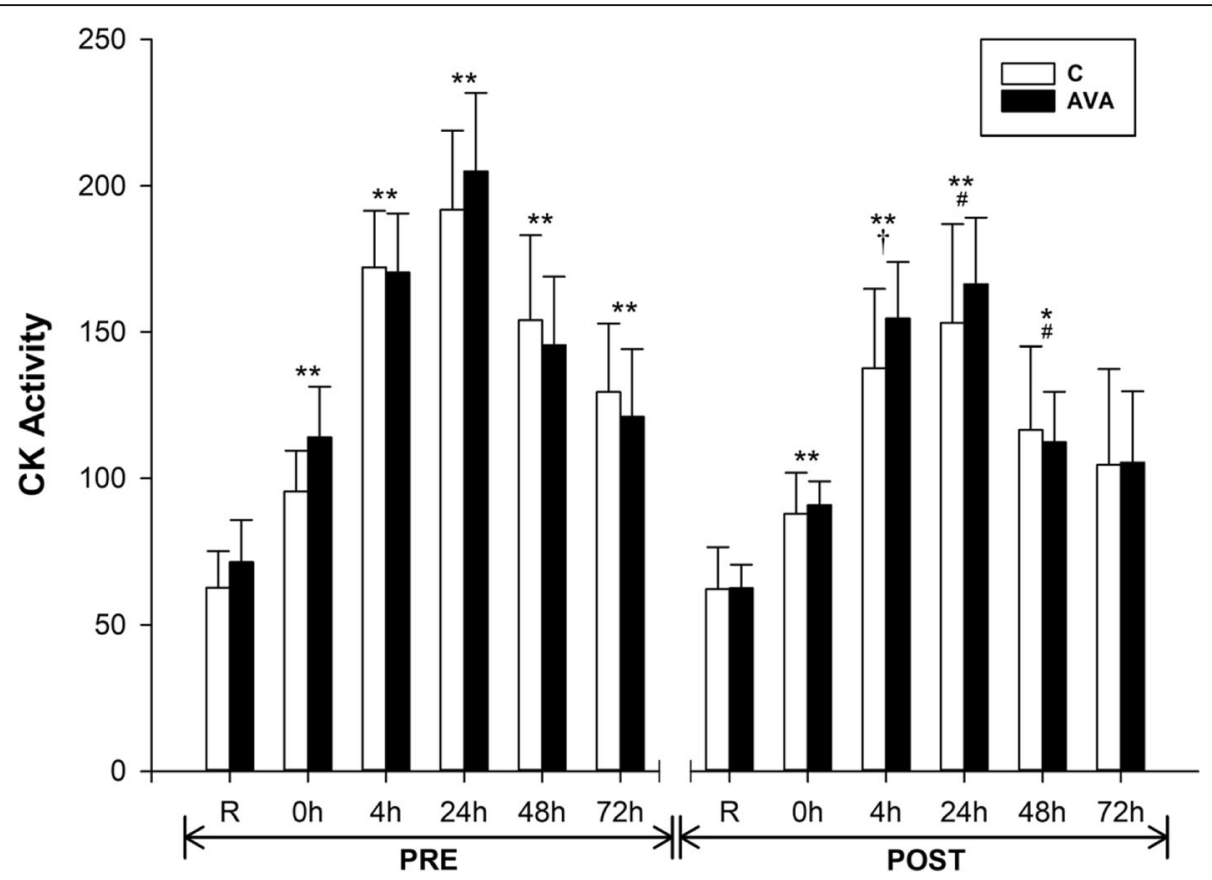

Fig. 2 Plasma CK activity. Data are shown as mean \pm SEM. Exercise effect: ${ }^{*} P<0.05$ or ${ }^{* *} P<0.01,0 \mathrm{~h} / 4 \mathrm{~h} / 24 \mathrm{~h} / 48 \mathrm{~h} / 72 \mathrm{~h}$ post-DR vs. Rest. Supplementation effect: ${ }^{\#} P<0.05$ or $+P=0.094$, POST vs. PRE regardless of time or AVA treatment. Interaction effect: $P<0.05$, timexsupplementation

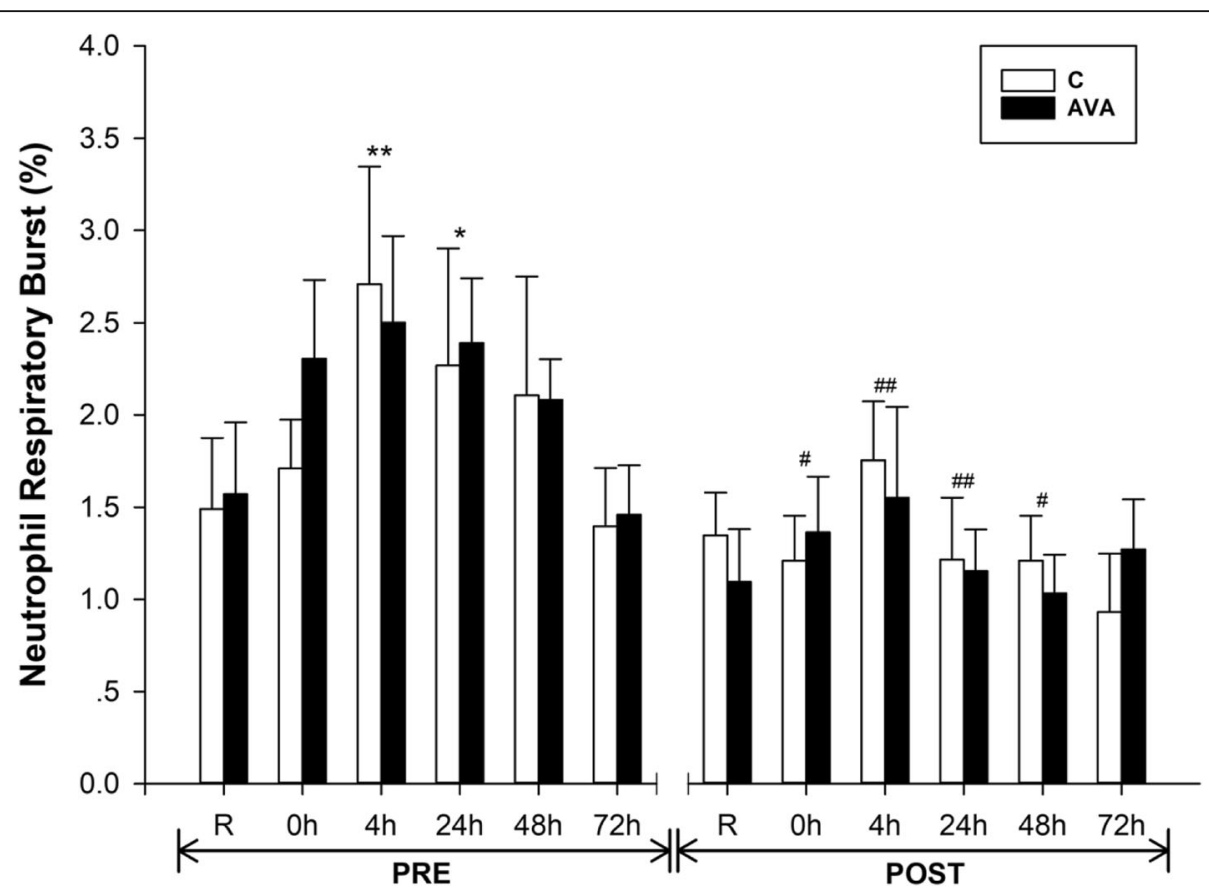

Fig. 3 Neutrophil Respiratory Burst (NRB). Data are shown as mean \pm SEM. Exercise effect: ${ }^{*} P<0.05$ or ${ }^{* *} P<0.01,0 \mathrm{~h} / 4 \mathrm{~h} / 24 \mathrm{~h} / 48 \mathrm{~h} / 72 \mathrm{~h}$ post-DR vs. Rest. Supplementation effect: ${ }^{\#} P<0.05$ or ${ }^{\# \#} P<0.01$, POST vs. PRE regardless of time or AVA treatment. Interaction effect: $P<0.05$, timexAVA; $P=$ 0.060 , supplementation $\times A V A ; P=0.059$, timexsupplementation 
increased at $0 \mathrm{~h}(P<0.01)$ and $4 \mathrm{~h}(P<0.05)$ after DR during PRE session, but returned to $\mathrm{R}$ values thereafter (Fig. 4). During POST session, however, G-CSF was elevated only at $0 \mathrm{~h}(P<0.05)$. Also, G-CSF levels were reduced at 24 h compared to its counterpart value during PRE session $(P=0.056)$. Furthermore, AVA-supplemented participants showed overall lower G-CSF levels than participants receiving $\mathrm{C}$ treatment during the POST session, but not during the PRE session $(P<0.05$, supplementation $\times$ AVA $)$.

\section{Plasma inflammatory and anti-inflammatory cytokines}

Plasma concentrations of IL-6, an important proinflammatory cytokine, was significantly increased at $0 \mathrm{~h}(P<0.01)$ and $4 \mathrm{~h}(P<0.01)$ after DR during PRE session, whereas it was elevated only at $0 \mathrm{~h}(P<0.01)$ during POST session (Fig. 5). In addition, IL-6 levels tended to be lower during POST session in the AVAsupplemented group than the $\mathrm{C}$ group $(P=0.082$, timexAVA).

IL-1Ra is a natural inhibitor of IL-1 $\beta$ and modulate a variety of IL-1 related immune and inflammatory responses. Plasma IL-1Ra concentrations showed a small but significant increase at $4 \mathrm{~h}$ during PRE $(P<0.01)$ and a trend toward a higher level at $4 \mathrm{~h}$ during POST $(P=$ 0.069) (Fig. 6). Also, IL-1Ra levels were significantly higher in AVA group than $C$ group during the POST session $(P<0.05$, timexsupplementation $\times$ AVA $)$.
Cell adhesion molecule and chemokine

To further test our hypothesis that AVA might inhibit DR-induced chemokine and adhesion molecule expression, we measured plasma sVCAM-1 and MCP-1 concentrations in response to DR (Fig. 7). sVCAM-1 levels were elevated at $0 \mathrm{~h}(P<0.01)$ and $4 \mathrm{~h}(P<0.01)$ after DR during both PRE and POST sessions. sVCAM-1 showed a tendency toward a lower response to DR at $24 \mathrm{~h}$ during POST than PRE $(P=0.079)$. Moreover, during POST, AVA-supplemented group had reduced sVCAM1 response to DR than $C$ group $(P<0.05$, timexAVA).

Another important chemokine, MCP-1, also clearly showed elevated plasma levels in response to DR at $0 \mathrm{~h}$ $(P<0.05)$ and $4 \mathrm{~h}(P<0.01)$ during $\mathrm{PRE}$, and at 0 and $4 \mathrm{~h}$ $(P<0.01)$ during POST (Fig. 8). However, during PRE, MCP-1 level returned to $\mathrm{R}$ level after $24 \mathrm{~h}$, but during POST, it was decreased at 24, $48(P<0.01)$ and $72 \mathrm{~h}$ $(P<0.05)$. A trend was revealed showing lower MCP-1 levels during POST compared to those during PRE over time $(P=0.064$, time $\times$ supplementation $)$.

\section{Pain rating scale}

DR significantly increased the muscle pain ratings among participants, shown during both PRE and POST sessions (Fig. 9). Pain reached the peak at 24 and $48 \mathrm{~h}$ $(P<0.01)$, but sustained through $72 \mathrm{~h}(P<0.01)$. However, pain levels were significantly lower during POST compared to PRE $(P<0.05$, timexsupplementation).

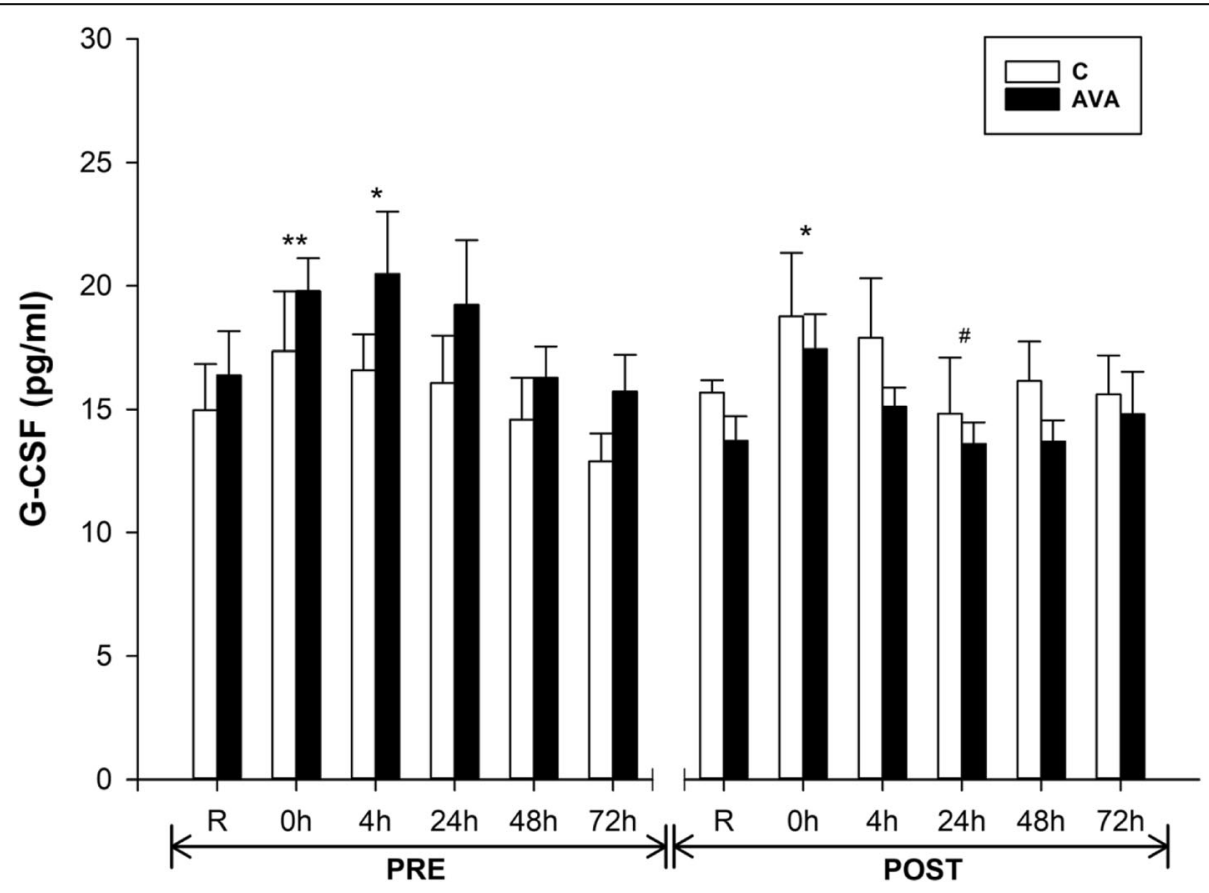

Fig. 4 Plasma G-CSF concentrations. Data are shown as mean \pm SEM. Exercise effect: ${ }^{*} P<0.05$ or ${ }^{* *} P<0.01,0 \mathrm{~h} / 4 \mathrm{~h} / 24 \mathrm{~h} / 48 \mathrm{~h} / 72 \mathrm{~h}$ post-DR vs. Rest. Supplementation effect: ${ }^{P} P=0.056$, POST vs. PRE regardless of time or AVA treatment. Interaction effect: $P<0.05$, supplementation $\times$ AVA 


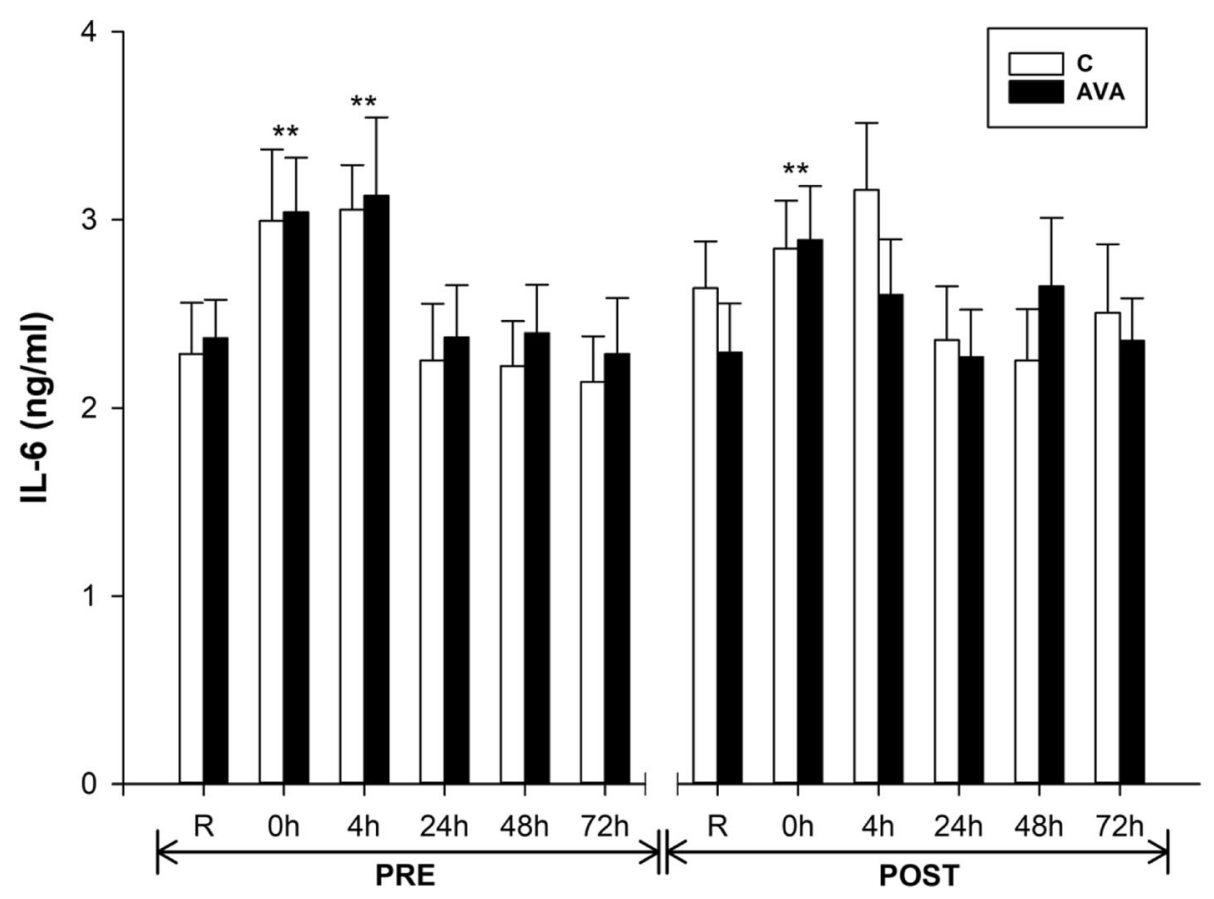

Fig. 5 Plasma IL-6 concentrations. Data are shown as mean \pm SEM. Exercise effect: ${ }^{* *} P<0.01,0 \mathrm{~h} / 4 \mathrm{~h} / 24 \mathrm{~h} / 48 \mathrm{~h} / 72 \mathrm{~h}$ post-DR vs. Rest. Interaction effect: $P=0.082$, timexAVA

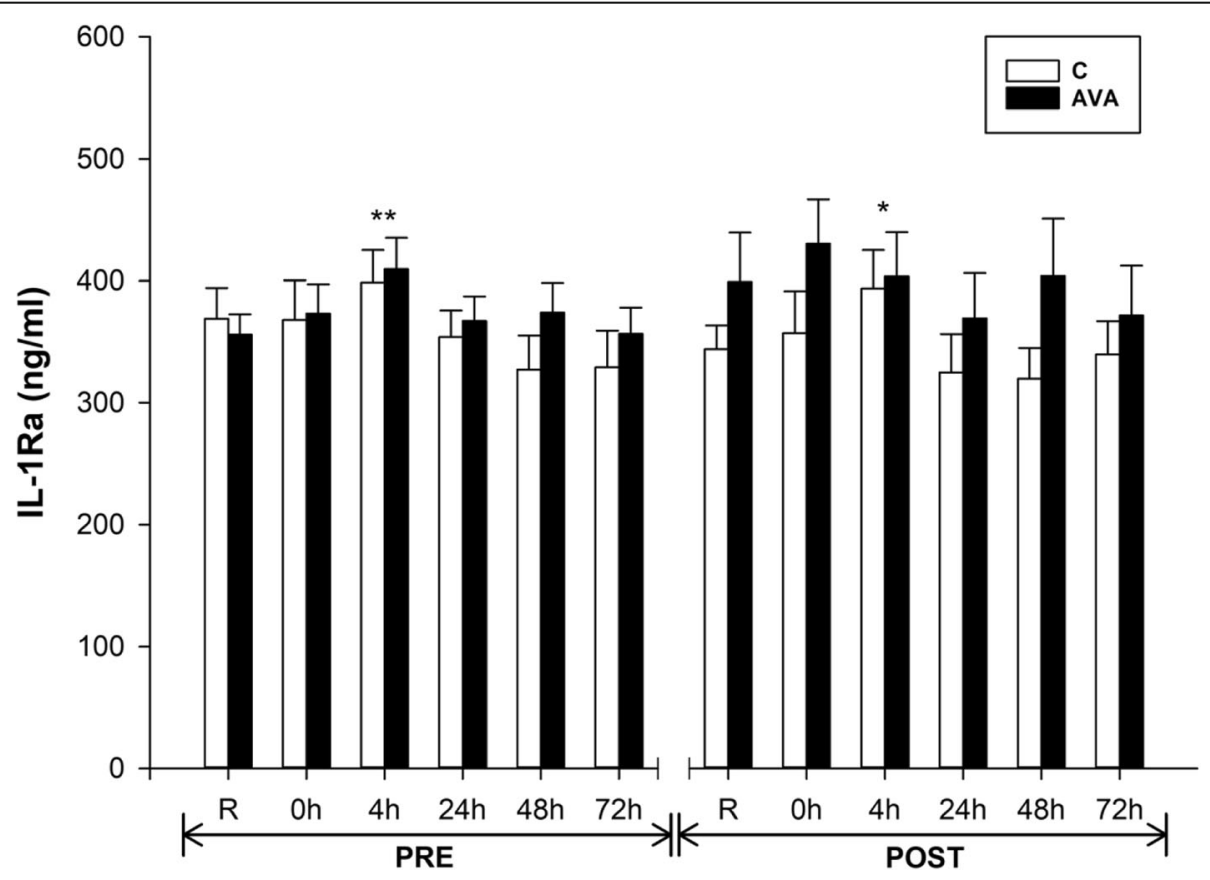

Fig. 6 Plasma IL-1Ra concentrations. Data are shown as mean \pm SEM. Exercise effect: ${ }^{*} P=0.069$ or ${ }^{* *} P<0.01,0 \mathrm{~h} / 4 \mathrm{~h} / 24 \mathrm{~h} / 48 \mathrm{~h} / 72 \mathrm{~h}$ post-DR vs. Rest. Interaction effect: $P<0.05$, timexsupplementation $\times$ AVA 


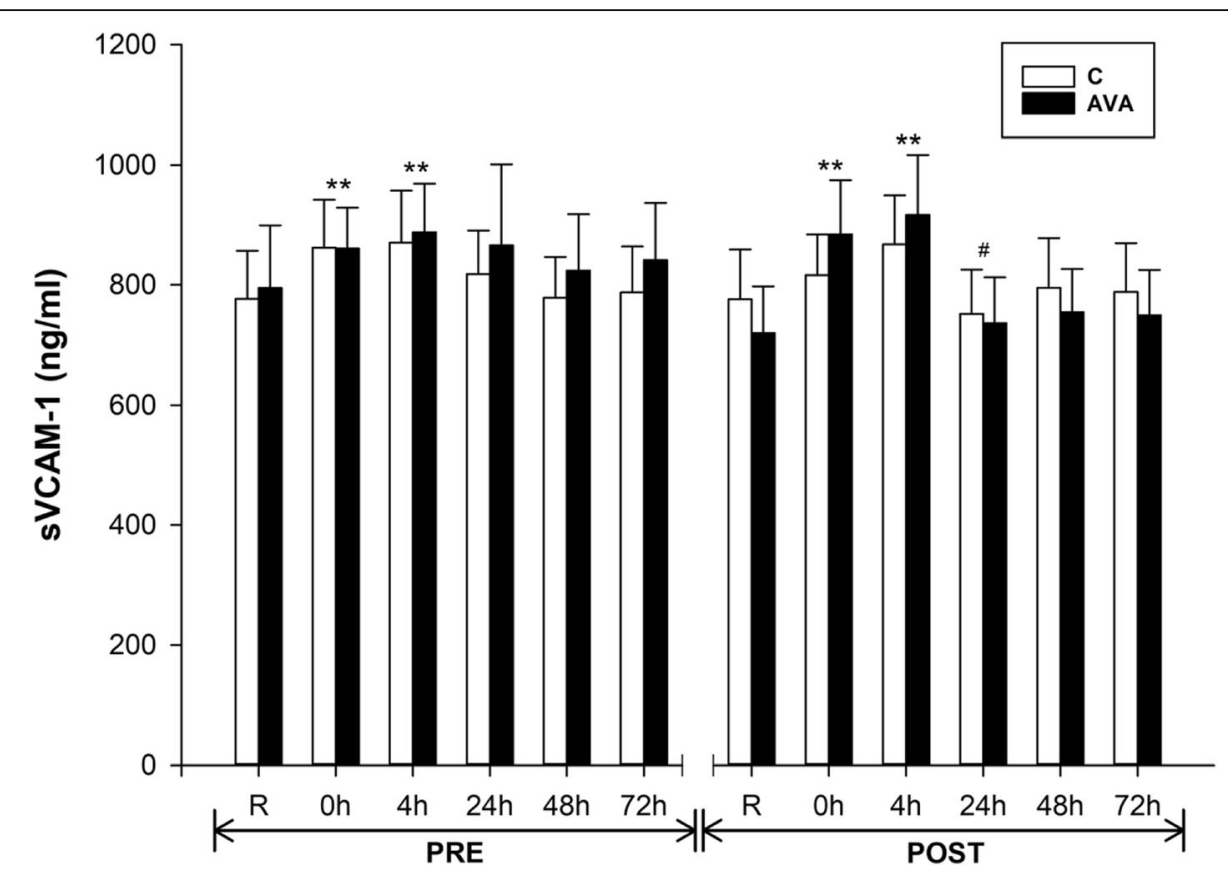

Fig. 7 Plasma sVCAM-1 concentrations. Data are shown as mean \pm SEM. Exercise effect: ${ }^{* *} P<0.01,0 \mathrm{~h} / 4 \mathrm{~h} / 24 \mathrm{~h} / 48 \mathrm{~h} / 72 \mathrm{~h}$ post-DR vs. Rest. Supplementation effect: ${ }^{\#} P=0.079$, POST vs. PRE regardless of time or AVA treatment. Interaction effect: $P<0.05$, timexAVA

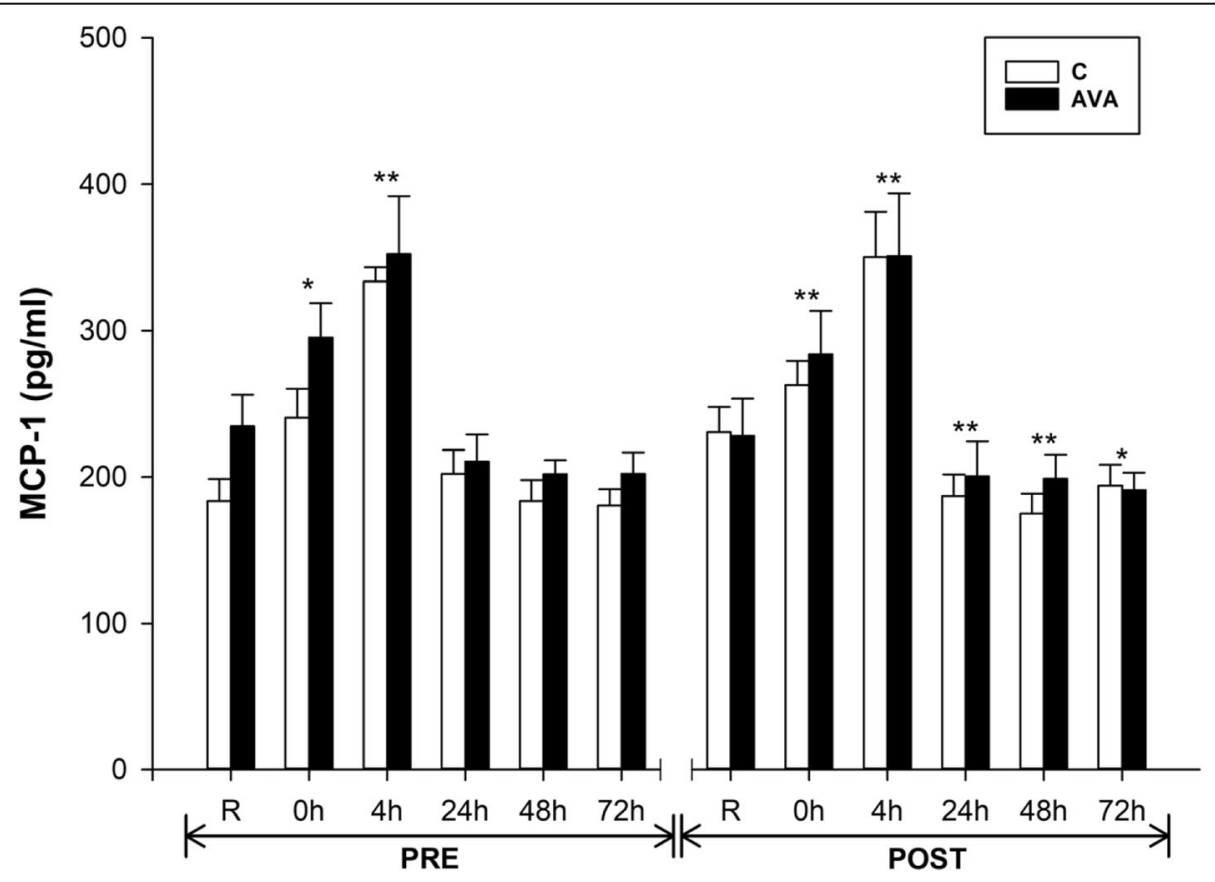

Fig. 8 Plasma MCP-1 concentrations. Data are shown as mean \pm SEM. Exercise effect: ${ }^{*} P<0.05$ or ${ }^{* *} P<0.01,0 \mathrm{~h} / 4 \mathrm{~h} / 24 \mathrm{~h} / 48 \mathrm{~h} / 72 \mathrm{~h}$ post-DR vs. Rest. Interaction effect: $P=0.064$, timexsupplementation 


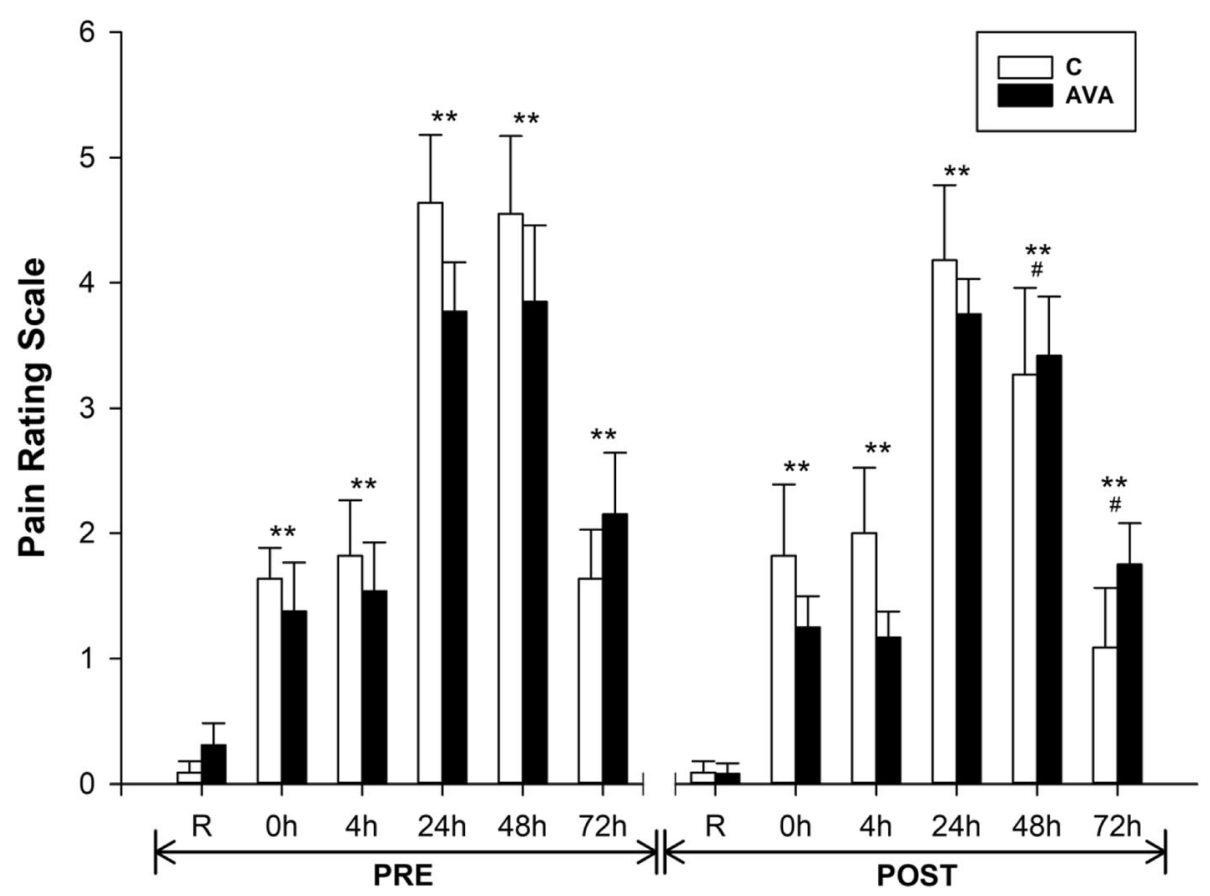

Fig. 9 Pain rating scale. Data are shown as mean \pm SEM. Exercise effect: ${ }^{* *} P<0.01,0 \mathrm{~h} / 4 \mathrm{~h} / 24 \mathrm{~h} / 48 \mathrm{~h} / 72 \mathrm{~h}$ post-DR vs. Rest. Supplementation effect: ${ }^{\#} P<0.05$, POST VS. PRE regardless of time or AVA treatment. Interaction effect: $P<0.05$, timexsupplementation

Furthermore, pain ratings showed significant lower levels at 48 and $72 \mathrm{~h}$ during POST than their PRE counterparts $(P<0.05)$.

\section{Discussion}

With the increasing demand for physical activity to promote a healthier lifestyle among the general public, maintaining proper antioxidant defense during exercise and sports is an important issue for muscle health [25, 26]. Eccentric contraction (EC), also known as lengthening contraction, is an integral element in high-intensity physical activity and sports [27, 28]. EC leads to oxidative stress, a status producing excessive ROS, and a variety of systemic and local inflammatory responses [29]. These adverse effects of EC were clearly demonstrated in the current study, as male and female young subjects, regardless of dietary supplementation, showed increased ROS generation from neutrophil respiratory burst (NRB), activated neutrophil expression, and overproduction of pro-inflammatory cytokines and chemokines, at $4-24 \mathrm{~h}$ post EC. Notably, these immunological and inflammatory responses were associated with enhanced muscle cell damage indicated by $\mathrm{CK}$ release and pain sensation, and in a delayed fashion typical of ECinduced muscle destruction [1-4].

Recent research indicates that supplementing large doses of antioxidants and/or anti-inflammatory drugs from pharmaceutical sources to suppress EC-induced inflammation can be detrimental, because they may interfere with and inhibit redox signaling pathways that elicit beneficial exercise adaptations [30,31]. Thus, seeking natural food sources of phytochemicals as dietary supplements with antioxidant and anti-inflammatory properties is highly desirable [32-34].

AVA were first discovered as phytoalexins with antimicrobial effect (inhibiting fungal germination in vivo) in response to infection [35, 36]. Over the past two decades, increasing research findings have revealed AVA's antioxidant and anti-inflammatory properties in both animal and human studies [12-14]. Direct evidence that AVA can reduce oxidative stress and inflammatory responses were reported by Koenig et al. [13, 14] in which young and older women supplemented with two AVAenriched cookies daily for 8 weeks decreased ROS generation from NRB and plasma CRP levels after a DR protocol similar to that in the present study. AVAtreated women groups demonstrated lower levels of mononuclear cell NF- $\mathrm{kB}$ activation and plasma IL-1 $\beta$ concentration. In the present study, we report several additional lines of evidence that not only substantiated the efficacy of AVA in mitigating inflammatory responses to stressful muscular activity reported in our earlier studies, but also shed some light on the mechanism of AVA protection. First, we confirmed that NRB plays a key role in ROS generation during EC and that chronic consumption of oats containing high AVA content can reduce this source of ROS generated from neutrophils (or monocytes) catalyzed by NADPH oxidase $[8$, 
37, 38] (Fig. 3). We further found that G-CSF might play an important role in facilitating NRB during DR, and AVA was able to attenuate this function (Fig. 4). CSFs are a group of cytokines that are released from injured skeletal muscles that promote the proliferation, differentiation and activation of hematopoietic cells after ECinduced muscle damage [39-41]. Previous research showed that plasma G-CSF levels were significantly elevated several hours after an acute bout of eccentric exercise and reached peak concentrations at 24 to $48 \mathrm{~h}$ post exercise [7, 42-45]. At the injury site, these recruited phagocytic cells remove and degrade damaged tissue by engulfing cellular debris (degranulation and phagocytosis) and releasing proteases and ROS $[6,46]$. ROSactivated NF- $\mathrm{kB}$ pathway amplifies the inflammation signals by expressing pro-inflammatory cytokines such as IL-1 $\beta$, IL- 6 and TNF- $\alpha$ and adhesion molecules to escalate inflammation [47]. Thus, our data showing that AVA-supplemented subjects has lower G-CSF levels in peripheral circulation suggest that this granulocytestimulating cytokine might facilitate neutrophils to generate ROS during DR and that by suppressing G-CSF expression AVA may ameliorate inflammatory process.

Second, our present study provided some new data on the effect of oats and AVA on downregulating plasma pro-inflammatory cytokines and chemokines in response to eccentric exercise. IL-6 can be derived from both macrophages and damaged muscle cells [48], and was found to increase its plasma concentration immediately and several hours after DR during both pre- and postsupplementation (Fig. 5), which was also reported in several previous studies [39, 44, 45, 49, 50]. After consuming AVA-enriched oat cookies for 8 weeks, the AVAsupplemented subjects showed an overall reduction of plasma IL-6 level $(P=0.082)$ despite being subjected to the same exercise stress as the control subjects. Although not statistically significant, this trend was consistent with our previous report that dietary AVA supplementation significantly reduced plasma IL-6 levels $24 \mathrm{~h}$ after DR in young women [14], and suppressed DRinduced plasma IL-1 $\beta$ and CRP levels in postmenopausal women [13]. We further demonstrated that antiinflammatory cytokine IL-Ra concentration was elevated in response to DR and that AVA treatment significantly increase plasma IL-1Ra levels during post-supplementation session (Fig. 6). As the IL-1 receptor antagonist (also known as IL-1 inhibitor), IL-1Ra blocks the binding activities of both IL- $1 \alpha$ and IL-1 $\beta$ to IL-1R thus attenuating a major source of inflammatory cytokine activation [51].

In addition to pro-inflammatory cytokines, we examined plasma levels of cell adhesion molecules (CAMs) such as VCAM-1 and MCP-1, which are known to facilitate neutrophil and macrophage infiltration into muscle cell to induce inflammatory response following damaging muscular contraction $[41,45,52]$. As a group of transmembrane proteins, CAMs are expressed on the surface of leukocytes and endothelial cells which involve the cell-to-cell interaction and migration from the circulation to the injured tissues [53-57]. We found that both sVCAM-1 and MCP-1 levels in the blood were increased in response to DR, which was consistent with previous reports $[44,45]$, whereas a significant attenuation of sVCAM-1 and a trend toward decreased MCP-1 were observed during the postsupplementation trials (Fig. 7, 8). Moreover, AVAsupplemented subjects showed lower levels of plasma sVCAM-1 than those consuming plain oats containing no AVA. Based on these findings, we speculate that AVA as well as other antioxidant ingredients in oats are capable of decreasing blood adhesion molecule expression thereby indirectly decreasing the migration and infiltration of monocytes during eccentric exercise $[4,58]$. We further speculate that these anti-inflammatory effects of AVA were conferred by the inhibition of NF-kB pathway, as demonstrated by previously reported studies $[13,14,22]$. Clear evidence on the role of NF- $\mathrm{KB}$ was derived in a recent study showing that t-butylhydroperoxide-stimulated TNF- $\alpha$ and IL- $1 \beta$ expressions in $\mathrm{C} 2 \mathrm{C} 12$ muscle cells were downregulated by three major fractions of AVA (A, B and C) [15]. Importantly, protein-ligand docking and molecular dynamics simulation studies revealed that AVA acted as an allosteric inhibitor for $\mathrm{I}_{\mathrm{K}} \mathrm{B}$ kinase (IKK $\beta$ ), the primary activator of NF-kB pathway. In another recently published study, AVA was found to inhibit TNF $\alpha$ induced ROS generation, NF- $\mathrm{kB}$ activation, and production of IL-1 $\beta$ and IL- 6 in C2C12 muscle cells [16]. These data suggest that the reduced plasma inflammatory profiles seen after AVA supplementation may result from attenuated NF-kB activation in skeletal muscle in response to eccentric exercise.

Finally, our present study indicated that chronic oat consumption not only ameliorated plasma inflammatory response to exercise stress, but also mitigated muscle damage as revealed by a lower plasma CK level (Fig. 2). Furthermore, pain sensation by the subjects, most likely related to DR-induced muscle damage, was reduced during post-supplementation trials especially among subjects treated with AVA-enriched diet (Fig. 9). These physiological data support the notion that besides the general benefits of oat consumption derived from various antioxidant and anti-hyperglycemic ingredients, long-term dietary supplementation of AVA may provide specific protection against detrimental impact of damaging muscular exertion.

\footnotetext{
Abbreviations

AVA: Avenanthramides; CAM: Cell adhesion molecule; CK: Creatine kinase; CRP: C-reactive protein; CSF: Colony stimulating factor; DHR: Dihydrorhodamine; DR: Downhill running; EC: Eccentric contraction; GCSF: Granulocyte colony-stimulating factor; ICAM: Intercellular adhesion molecule; IKK: IKB kinase; IL: Interleukin; IL-1Ra: Interleukin-1 receptor antagonist; MCP: Monocyte chemotactic protein; NF-kB: Nuclear factor-kB;
} 
NRB: Neutrophil respiratory burst; ROS: Reactive oxygen species; TNFa: Tumor necrosis factor-a; sVCAM: Soluble vascular cell adhesion molecule

\section{Acknowledgements}

We thank Dr. Chounghun Kang, and Dr. Dongwook Yeo for their technical support and advice. We thank Dr. Zachary Pope for his support on statistical analysis.

\section{Authors' contributions}

T. Zhang, T. Zhao, Y.Z. and T.L. performed the experiments. T. Zhang analyzed data and wrote the manuscript. G.G. and J.E. provided oat flour. J.J. and Y.C. provided editorial feedback to the manuscript. T. Zhang and L.L.J. designed study and L.L.J. supervised the project. All authors discussed the results and commented on the manuscript. The author(s) read and approved the final manuscript.

\section{Funding}

The project was funded by PepsiCo Inc. and Ceapro Inc.

\section{Availability of data and materials}

The datasets used and/or analyzed during the current study are available from the corresponding author on reasonable request.

\section{Ethics approval and consent to participate}

All participants in this study have signed informed consent approved by the University of Minnesota-Institutional Review Board (IRB). IRB Code Number: 1509 M78581.

\section{Consent for publication}

Not applicable.

\section{Competing interests}

J. J. and Y. C. are employees of PepsiCo Inc., which manufactures oatmeal products under the brand name Quaker Oats ${ }^{\oplus}$. The views expressed in this article are those of the authors and do not necessarily reflect the opinion or policies of PepsiCo Inc

\section{Author details}

'Laboratory of Exercise and Sports Nutrition (LESN), Department of Kinesiology, The University of Texas at San Antonio, San Antonio, TX 78249, USA. ${ }^{2}$ Laboratory of Physiological Hygiene and Exercise Science (LPHES), School of Kinesiology, University of Minnesota-Twin Cities, Minneapolis, MN 55455, USA. ${ }^{3}$ Ceapro Inc., Edmonton, AB T6E 6W2, Canada. ${ }^{4}$ PepsiCo R\&D Nutrition, Barrington, IL 60010, USA.

\section{Received: 11 November 2019 Accepted: 9 July 2020}

Published online: 25 July 2020

\section{References}

1. Armstrong RB. Mechanisms of exercise-induced delayed onset muscular soreness: a brief review. Med Sci Sports Exerc. 1984;16(6):529-38.

2. Cheung K, Hume P, Maxwell L. Delayed onset muscle soreness : treatment strategies and performance factors. Sports Med. 2003;33(2):145-64.

3. Gulick DT, Kimura IF, Sitler M, Paolone A, Kelly JD. Various treatment techniques on signs and symptoms of delayed onset muscle soreness. Athl Train. 1996;31(2):145-52.

4. Proske U, Morgan DL. Muscle damage from eccentric exercise: mechanism, mechanical signs, adaptation and clinical applications. J Physiol Lond. 2001; 537(Pt 2):333-45.

5. Paulsen G, Mikkelsen UR, Raastad T, Peake JM. Leucocytes, cytokines and satellite cells: what role do they play in muscle damage and regeneration following eccentric exercise? Exerc Immunol Rev. 2012;18:42-97.

6. Butterfield TA, Best TM, Merrick MA. The dual roles of neutrophils and macrophages in inflammation: a critical balance between tissue damage and repair. J Athl Train. 2006;41(4):457-65.

7. Paulsen G, Crameri R, Benestad HB, Fjeld JG, Mørkrid L, Hallén J, et al. Time course of leukocyte accumulation in human muscle after eccentric exercise. Med Sci Sports Exerc. 2010;42(1):75-85.

8. Pyne DB, Smith JA, Baker MS, Telford RD, Weidemann MJ. Neutrophil oxidative activity is differentially affected by exercise intensity and type. J Sci Med Sport. 2000;3(1):44-54.
9. Tidball JG, Villalta SA. Regulatory interactions between muscle and the immune system during muscle regeneration. Am J Phys Regul Integr Comp Phys. 2010;298(5):R1173-87.

10. Howatson G, van Someren KA. The prevention and treatment of exerciseinduced muscle damage. Sports Med. 2008;38(6):483-503.

11. Collins FW. Oat phenolics: avenanthramides, novel substituted Ncinnamoylanthranilate alkaloids from oat groats and hulls. J Agric Food Chem. 1989;37(1):60-6.

12. Ji LL, Lay D, Chung E, Fu Y, Peterson DM. Effects of avenanthramides on oxidant generation and antioxidant enzyme activity in exercised rats. Nutr Res. 2003:23(11):1579-90.

13. Koenig R, Dickman JR, Kang C, Zhang T, Chu Y-F, Ji LL. Avenanthramide supplementation attenuates exercise-induced inflammation in postmenopausal women. Nutr J. 2014;13:21

14. Koenig RT, Dickman JR, Kang C-H, Zhang T, Chu Y-F, Ji LL. Avenanthramide supplementation attenuates eccentric exercise-inflicted blood inflammatory markers in women. Eur J Appl Physiol. 2016;116(1):67-76.

15. Kang C, Shin WS, Yeo D, Lim W, Zhang T, Ji LL. Anti-inflammatory effect of avenanthramides via NF-kB pathways in C2C12 skeletal muscle cells. Free Radic Biol Med. 2018;117:30-6.

16. Yeo D, Kang C, Zhang T, Ji LL. Avenanthramides attenuate inflammation and atrophy in muscle cells. J Sport Health Sci. 2019;8(2):189-95.

17. Zhang T, Ji LL. Avenanthramides. In: Whole grains and their bioactives: Wiley; 2019. p. 307-38. [cited 2019 May 13]. Available from: https:// onlinelibrary.wiley.com/doi/abs/10.1002/9781119129486.ch11.

18. Koenig RT, Dickman JR, Wise ML, Ji LL. Avenanthramides are bioavailable and accumulate in hepatic, cardiac, and skeletal muscle tissue following oral gavage in rats. J Agric Food Chem. 2011;59(12):6438-43.

19. Chen C-YO, Milbury PE, Collins FW, Blumberg JB. Avenanthramides are bioavailable and have antioxidant activity in humans after acute consumption of an enriched mixture from oats. J Nutr. 2007;137(6):1375-82.

20. Zhang T, Shao J, Gao Y, Chen C, Yao D, Chu YF, et al. Absorption and elimination of oat avenanthramides in humans after acute consumption of oat cookies. Oxid Med Cell Longev. 2017; [cited 2019 Aug 26]. Available from: https://www.ncbi.nlm.nih.gov/pmc/articles/PMC5752969/.

21. Liu L, Zubik L, Collins FW, Marko M, Meydani M. The antiatherogenic potential of oat phenolic compounds. Atherosclerosis. 2004;175(1):39-49.

22. Guo W, Wise ML, Collins FW, Meydani M. Avenanthramides, polyphenols from oats, inhibit IL-1 $\beta$-induced NF-kB activation in endothelial cells. Free Radic Biol Med. 2008:44(3):415-29.

23. Nie L, Wise ML, Peterson DM, Meydani M. Avenanthramide, a polyphenol from oats, inhibits vascular smooth muscle cell proliferation and enhances nitric oxide production. Atherosclerosis. 2006;186(2):260-6.

24. Garber CE, Blissmer B, Deschenes MR, Franklin BA, Lamonte MJ, Lee I-M, et al. American College of Sports Medicine position stand. Quantity and quality of exercise for developing and maintaining cardiorespiratory, musculoskeletal, and neuromotor fitness in apparently healthy adults: guidance for prescribing exercise. Med Sci Sports Exerc. 2011;43(7):1334-59.

25. Ji LL. Exercise-induced modulation of antioxidant defense. Ann N Y Acad Sci. 2002;959:82-92.

26. Ji LL, Gomez-Cabrera M-C, Vina J. Role of free radicals and antioxidant signaling in skeletal muscle health and pathology. Infect Disord Drug Targets. 2009;9(4):428-44.

27. Pedersen BK, Toft AD. Effects of exercise on lymphocytes and cytokines. Br J Sports Med. 2000;34(4):246-51.

28. Proske U, Allen TJ. Damage to skeletal muscle from eccentric exercise. Exerc Sport Sci Rev. 2005;33(2):98-104.

29. Liao P, Zhou J, Ji LL, Zhang Y. Eccentric contraction induces inflammatory responses in rat skeletal muscle: role of tumor necrosis factor-alpha. Am J Phys Regul Integr Comp Phys. 2010;298(3):R599-607.

30. Ji LL, Kang C, Zhang Y. Exercise-induced hormesis and skeletal muscle health. Free Radic Biol Med. 2016;98:113-22.

31. Ristow M, Zarse K, Oberbach A, Klöting N, Birringer M, Kiehntopf M, et al. Antioxidants prevent health-promoting effects of physical exercise in humans. Proc Natl Acad Sci U S A. 2009;106(21):8665-70.

32. Fusco D, Colloca G, Lo Monaco MR, Cesari M. Effects of antioxidant supplementation on the aging process. Clin Interv Aging. 2007;2(3):377-87.

33. Pham-Huy LA, He H, Pham-Huy C. Free radicals, antioxidants in disease and health. Int J Biomed Sci. 2008:4(2):89-96.

34. Willcox JK, Ash SL, Catignani GL. Antioxidants and prevention of chronic disease. Crit Rev Food Sci Nutr. 2004;44(4):275-95. 
35. Mayama S, Matsuura Y, lida H, Tani T. The role of avenalumin in the resistance of oat to crown rust, Puccinia coronata f. sp. avenae. Physiol Plant Pathol. 1982;20(2):189-99.

36. Miyagawa H, Ishihara A, Nishimoto T, Ueno T, Mayama S. Induction of avenanthramides in oat leaves inoculated with crown rust fungus, Puccinia coronata f. sp. avenae. Biosci Biotechnol Biochem. 1995;59(12):2305-6.

37. Dahlgren C, Karlsson A. Respiratory burst in human neutrophils. J Immunol Methods. 1999;232(1-2):3-14.

38. Pizza FX, Cavender D, Stockard A, Baylies H, Beighle A. Anti-inflammatory doses of ibuprofen: effect on neutrophils and exercise-induced muscle injury. Int I Sports Med. 1999;20(2):98-102.

39. Petersen EW, Ostrowski K, Ibfelt T, Richelle M, Offord E, Halkjaer-Kristensen J, et al. Effect of vitamin supplementation on cytokine response and on muscle damage after strenuous exercise. Am J Phys Cell Phys. 2001;280(6): C1570-5.

40. Pizza FX, Mitchell JB, Davis BH, Starling RD, Holtz RW, Bigelow N. Exerciseinduced muscle damage: effect on circulating leukocyte and lymphocyte subsets. Med Sci Sports Exerc. 1995;27(3):363-70.

41. Smith LL, Anwar A, Fragen M, Rananto C, Johnson R, Holbert D. Cytokines and cell adhesion molecules associated with high-intensity eccentric exercise. Eur J Appl Physiol. 2000;82(1-2):61-7.

42. Paulsen G, Benestad HB, Strøm-Gundersen I, Mørkrid L, Lappegård KT, Raastad T. Delayed leukocytosis and cytokine response to high-force eccentric exercise. Med Sci Sports Exerc. 2005;37(11):1877-83.

43. Hirose L, Nosaka K, Newton M, Laveder A, Kano M, Peake J, et al. Changes in inflammatory mediators following eccentric exercise of the elbow flexors. Exerc Immunol Rev. 2004;10:75-90.

44. Peake JM, Suzuki K, Wilson G, Hordern M, Nosaka K, Mackinnon L, et al. Exercise-induced muscle damage, plasma cytokines, and markers of neutrophil activation. Med Sci Sports Exerc. 2005;37(5):737-45.

45. Peake JM, Suzuki K, Hordern M, Wilson G, Nosaka K, Coombes JS. Plasma cytokine changes in relation to exercise intensity and muscle damage. Eur J Appl Physiol. 2005;95(5-6):514-21.

46. Pereira Panza VS, Diefenthaeler F, da Silva EL. Benefits of dietary phytochemical supplementation on eccentric exercise-induced muscle damage: is including antioxidants enough? Nutrition. 2015;31(9):1072-82.

47. Peake J, Nosaka K, Suzuki K. Characterization of inflammatory responses to eccentric exercise in humans. Exerc Immunol Rev. 2005;11:64-85.

48. Pedersen BK, Steensberg A, Schjerling P. Muscle-derived interleukin-6: possible biological effects. J Physiol. 2001;536(Pt 2):329-37.

49. Croisier JL, Camus G, Venneman I, Deby-Dupont G, Juchmès-Ferir A, Lamy $M$, et al. Effects of training on exercise-induced muscle damage and interleukin 6 production. Muscle Nerve. 1999;22(2):208-12.

50. Toft AD, Jensen LB, Bruunsgaard H, Ibfelt T, Halkjaer-Kristensen J, Febbraio $M$, et al. Cytokine response to eccentric exercise in young and elderly humans. Am J Phys Cell Phys. 2002;283(1):C289-95.

51. Arend WP, Malyak M, Guthridge CJ, Gabay C. Interleukin-1 receptor antagonist: role in biology. Annu Rev Immunol. 1998;16:27-55.

52. Prame Kumar K, Nicholls AJ, Wong CHY. Partners in crime: neutrophils and monocytes/macrophages in inflammation and disease. Cell Tissue Res. 2018. 371(3):551-65.

53. Carlos TM, Harlan JM. Leukocyte-endothelial adhesion molecules. Blood. 1994;84(7):2068-101

54. Edelman GM. Cell adhesion molecules. Science. 1983;219(4584):450-7.

55. Elangbam CS, Qualls CW, Dahlgren RR. Cell adhesion molecules--update. Vet Pathol. 1997;34(1):61-73

56. Pigott R, Dillon LP, Hemingway $H$, Gearing AJ. Soluble forms of E-selectin, ICAM-1 and VCAM-1 are present in the supernatants of cytokine activated cultured endothelial cells. Biochem Biophys Res Commun. 1992;187(2):5849

57. Nakai K, Itoh C, Kawazoe K, Miura Y, Sotoyanagi H, Hotta K, et al. Concentration of soluble vascular cell adhesion molecule-1 (VCAM-1) correlated with expression of VCAM-1 mRNA in the human atherosclerotic aorta. Coron Artery Dis. 1995;6(6):497-502.

58. Deshmane SL, Kremlev S, Amini S, Sawaya BE. Monocyte chemoattractant protein-1 (MCP-1): an overview. J Interf Cytokine Res. 2009;29(6):313-26.

\section{Publisher's Note}

Springer Nature remains neutral with regard to jurisdictional claims in published maps and institutional affiliations.

Ready to submit your research? Choose BMC and benefit from:

- fast, convenient online submission

- thorough peer review by experienced researchers in your field

- rapid publication on acceptance

- support for research data, including large and complex data types

- gold Open Access which fosters wider collaboration and increased citations

- maximum visibility for your research: over $100 \mathrm{M}$ website views per year

At BMC, research is always in progress.

Learn more biomedcentral.com/submissions 